\title{
Optimal level of positive end-expiratory pressure during nasal continuous airway pressure for severe bronchiolitis: a prospective study
}

\author{
Lijuan Yin ${ }^{1 \#}$, Linwei Li ${ }^{2 \#}$, Donghong Peng ${ }^{1}$, Wei Chen ${ }^{1}$ \\ ${ }^{1}$ Department of Respiratory Medicine, Children's Hospital of Chongqing Medical University, National Clinical Research Center for Child \\ Health and Disorders, Ministry of Education Key Laboratory of Child Development and Disorders, China International Science and Technology \\ Cooperation Base of Child Development and Critical Disorders, Chongqing Key Laboratory of Pediatrics, Chongqing, China; ${ }^{2}$ Department of \\ Pediatrics, Jiangjin Central Hospital of Chongqing, Chongqing, China \\ Contributions: (I) Conception and design: L Yin, L Li; (II) Administrative support: L Yin; (III) Provision of study materials or patients: D Peng, W \\ Chen; (IV) Collection and assembly of data: L Yin, L Li; (V) Data analysis and interpretation: L Yin, L Li; (VI) Manuscript writing: All authors; (VII) \\ Final approval of manuscript: All authors. \\ "These authors contributed equally to this work. \\ Correspondence to: Lijuan Yin. The Second Ward of Respiratory Center, Children's Hospital Affiliated to Chongqing Medical University, Chongqing \\ 400014, China. Email: yudishengyin4356@sina.com.
}

Background: Nasal continuous positive airway pressure (nCPAP) has been increasingly applied in the pediatric setting. However, there is no uniform standard for setting and titrating positive end-expiratory pressure (PEEP) level, which is paramount to the effectiveness of the treatment. This study aimed to investigate the optimal parameters for nCPAP in the treatment of severe bronchiolitis based on clinical efficacy and pulmonary function parameters.

Methods: A before-after prospective study was conducted with a total of 152 study subjects. These 152 hospitalized patients with severe bronchiolitis were treated and observed from December 2018 to February 2019. Comparisons were made between subjects for clinical symptoms, oxygenation improvement, correction of $\mathrm{CO}_{2}$ retention, degree of airway obstruction and respiratory mechanics improvement between three different positive end-expiratory pressure levels (PEEP).

Results: nCPAP could effectively improve the clinical manifestations, blood gas analysis, pulmonary function and respiratory muscle energy consumption. The m-WCAS score, $\mathrm{PaCO}_{2}$, TPTEF/TE, VPEF/ VE, respiratory system compliance (Crs) and resistance (Rrs) were significantly different at different PEEP levels $(\mathrm{P}<0.05)$. Although there were no hemodynamic changes at peep parameter levels in the three groups. Group 2 (PEEP: $6 \mathrm{cmH}_{2} \mathrm{O}$ ) had optimal clinical effects, and improvement in airway obstruction and respiratory mechanics compared with the group 1 (PEEP: $4 \mathrm{cmH}_{2} \mathrm{O}$ ) and the group $3\left(\mathrm{PEEP}: 7 \mathrm{cmH}_{2} \mathrm{O}\right.$ ).

Conclusions: PEEP of $6 \mathrm{cmH}_{2} \mathrm{O}$ via nCPAP is considered as the optimal level in the treatment of infants with severe bronchiolitis.

Keywords: Severe bronchiolitis; nasal continuous positive airway pressure (nCPAP); positive end-expiratory pressure (PEEP); pediatrics

Submitted Apr 11, 2021. Accepted for publication Jun 11, 2021.

doi: $10.21037 / \mathrm{tp}-21-205$

View this article at: https://dx.doi.org/10.21037/tp-21-205 


\section{Introduction}

As diagnosis and treatment of bronchiolitis has progressed, nasal continuous positive airway pressure (nCPAP) has been increasingly applied in the pediatric setting. Due to its simplicity, low cost, easy operation, and minimal side effects, this method has become a primary treatment of severe bronchiolitis in recent years (1-3). In China, respiratory departments have demonstrated wide application and good clinical efficacy of nCPAP; however, some key problems have not been solved. There is no uniform standard for setting and titrating positive endexpiratory pressure (PEEP) level, which is paramount to the effectiveness of the treatment $(4,5)$. This prospective study between December 2018 and February 2019, compared the clinical efficacy of nCPAP at various PEEP levels in the treatment of severe bronchiolitis; changes in the degree of airway obstruction and respiratory mechanics parameters were also assessed. This study aimed to establish an optimal PEEP for nCPAP and provide more evidence for the clinical application of nCPAP in severe bronchiolitis.

We present the following article in accordance with the STROBE reporting checklist (available at https://dx.doi. org/10.21037/tp-21-205).

\section{Methods}

\section{Study subjects}

Inclusion criteria for this study required that the participants: (I) were hospitalized children aged $\leq 1$ year; (II) met the diagnostic criteria of bronchiolitis (6); (III) displayed tachypnea with three concave sign or flapping of nasal wings; or $50 \mathrm{mmH}_{2} \mathrm{O} \leq \mathrm{PaCO}_{2} \leq 60 \mathrm{cmH}_{2} \mathrm{O}$ or $\mathrm{TcSO}_{2}$ $\leq 95 \%$ when oxygen by nasal catheter $\geq 5 \mathrm{~L} / \mathrm{min}$. Patients who met items 1 and 2, and displayed at least one of the clinical signs in item 3, were included.

Exclusion criteria for the study were: (I) chronic lung disease; (II) inherited metabolic diseases; (III) neuromuscular disorders with weakness of respiratory muscles; (IV) congenital heart disease with significant hemodynamic changes; (V) chest imaging has indicated pneumothorax before using ventilator; (VI) patients who had used invasive ventilation during the same hospitalization; (VII) hemodynamic instability; (VIII) acidosis with $\mathrm{pH}<7.2$. Patients who met any of the above criteria were excluded.

All procedures performed in this study involving human participants were in accordance with the Declaration of Helsinki (as revised in 2013). The study was approved by the institutional review board Children's Hospital Chongqing Medical University (No. 056/2016) and written informed consent was obtained from all patients.

\section{nCPAP (7) and grouping}

All treatments were performed in the junior intensive care beds of our respiratory center. Clinical symptoms and infant pulmonary function were measured in all children with bronchiolitis by specialists in our center. The children who met the screening criteria were treated with unified drug treatment and nCPAP. Following application of nCPAP, the children were given necessary pacification, sedation and then placed with correct body position. Additionally, protection of the mucosa in contact with the tube, and maintenance of unobstructed airway, were given for the purpose of effective nCPAP.

Routine indicators such as respiratory rate (RR), heart rate (HR) and blood pressure were monitored. The patients were randomly divided into three groups: group 1 (PEEP: $4 \mathrm{cmH}_{2} \mathrm{O}$ ), group 2 (PEEP: $6 \mathrm{cmH}_{2} \mathrm{O}$ ), and group 3 (PEEP: $7 \mathrm{cmH}_{2} \mathrm{O}$ ). The clinical manifestations of the children were assessed, and parameters of arterial blood gas analysis, pulmonary function and respiratory mechanics were measured. Chest X-rays were performed before and 12 hours after the nCPAP application to examine the occurrence of mucocutaneous injury. The noninvasive ventilation with different PEEP levels was all immediately stopped to invasive respiratory therapy through endotracheal intubation if the children developed the following symptoms: dyspnea; no remission or aggravation of respiratory muscle fatigue; $\mathrm{PaO}_{2} \leq 60 \mathrm{mmHg}$ when PEEP $>6 \mathrm{cmH}_{2} \mathrm{O}$ and $\mathrm{FiO}_{2} \geq 60 \%$; increase of $\mathrm{PaCO}_{2}$ in a short time after active airway management.

\section{Noninvasive respiratory support equipment and parameter setting}

The Stephanie CPAP-C neonatal ventilation system (Fritz Stephan GmbH, Germany) was used. The initial parameters were: oxygen concentration: $\leq 50 \%$; PEEP: $4-10 \mathrm{cmH}_{2} \mathrm{O}$; peak inspiratory pressure: $15-100 \mathrm{cmH}_{2} \mathrm{O} ; \mathrm{FiO}_{2}: 0.21-$ 0.60 (on the basis of percutaneous oxygen saturation at $85-93 \%)$, RR: $20-60$ breaths/min. The patients underwent ventilator weaning when $\mathrm{RR} \leq 30$ breaths/min, $\mathrm{FiO}_{2} \leq 40 \%$, PEEP $<4 \mathrm{cmH}_{2} \mathrm{O}, \mathrm{PaO}_{2} \geq 70 \mathrm{mmHg}$ and 
$\mathrm{PaCO}_{2}<40 \mathrm{mmHg}$.

\section{Determination of parameters of pulmonary function and respiratory mechanics}

The MasterScreen BabyBody system (JAEGER, Germany) was used for lung function testing. Calibrations were performed prior to the examination. After sedation and checking the airway was unobstructed, participants were placed in the supine position with the mask firmly fitted over the mouth and nose to ensure no air leakage. Participants were measured before application of the nCPAP and 12 hours after application. Relevant parameters reflecting airway obstruction were also recorded, including inspiratory time (Ti), inspiratory time fraction (Ti/Ttot), ratio of time to peak tidal expiratory flow to total expiratory time (TPTEF/TE), and ratio of volume at peak tidal expiratory flow to expiratory tidal volume (VPTEF/VE) (8). Due to the age of the infants, passive respiratory mechanics parameters (9) were assessed, including static compliance of respiratory system (Crs), which reflected the elasticity of respiratory system (i.e., lung and chest wall), and resistance of respiratory system (Rrs), including the chest wall, lung tissue and respiratory tract.

\section{Observation parameters}

Baseline data and outcome measures included: age, gender, body weight, course of disease before utilization of the ventilator, RR, HR, body temperature, blood pressure, $\mathrm{m}$-WCAS score, arterial blood gas analysis parameters $\left(\mathrm{PaO}_{2}, \mathrm{PaO}_{2} / \mathrm{FiO}_{2}, \mathrm{PaCO}_{2}\right)$, pulmonary function parameters (tidal volume, TPTEF/TE, VPEF/VE), respiratory mechanics parameters (Crs, Rrs), duration of non-invasive respiratory support, incidence of pneumothorax, abdominal distension, and mucocutaneous injuries.

\section{Statistical analysis}

Statistical analysis was completed using the SPSS 18.0 statistical package. Measurement data were expressed as $\bar{x} \pm \mathrm{s}$, while enumeration data was expressed as percentage or ratio. Variance was used to compare measurement data. Enumeration data with normal distribution was compared using Chi-square test, while enumeration data with nonnormal distribution was compared using Wilcoxon ranksum test. Statistical significance was set at $\mathrm{P}<0.05$.

\section{Results}

\section{Clinical data}

A total of 152 patients met the inclusion criteria, while a further 34 patients were excluded based on the exclusion criteria. Before application of nCPAP treatment, baseline patient data was collected. Baseline data was as follows: average age of onset $4.5 \pm 2.41$ months; number of males: 95 cases; average body weight: $5.35 \pm 1.32 \mathrm{~kg}$; RR: $64 \pm 2.15$ breaths/min; HR: $158 \pm 5.44 \mathrm{bpm}$; average body temperature: $36.4 \pm 1.41^{\circ} \mathrm{C}$; average systolic blood pressure: $92 \pm 10.21 \mathrm{mmHg}$; average diastolic blood pressure: $54 \pm 8.16 \mathrm{mmHg}$; average onset time: $4.5 \pm 1.7$ days. Pathogen detection revealed 101 respiratory syncytial virus (RSV) positive cases, 21 parainfluenza virus-3 (PIV-3) positive cases, and 23 positive cases for other viral pathogens. In addition, the leading combined bacterial infections was Haemophilus influenzae, which occurred in 15 cases.

There were no significant difference in age, gender, course of disease, RR, HR, blood pressure and RSV positive rate among the three groups $(\mathrm{P}>0.05)$ (Table 1). During nCPAP treatment, 8 patients were changed to invasive respiratory support, and the overall response rate of nCPAP was $95.04 \%$. No patients developed pneumothorax, abdominal distension, or mucocutaneous injuries. Prior to nCPAP, chest imaging mostly showed strip and floc shadow in 147 cases, of which eight cases had segmental consolidation of the lung. The other five patients were changed to invasive respiratory support, three of whom were malnourished and two of whom had multi-segmental lung consolidation. The average hospital stay was $5.1 \pm 14$ days, and the average treatment time of nCPAP treatment was $48 \pm 2.56$ hours.

\section{Comparison of parameters of clinical manifestation before and after nCPAP treatment}

There is no uniform standard for assessing the severity of wheezing in pediatrics. At present, m-WCAS score (9) is the most common criteria used to quantitatively score respiratory symptoms (nodding respiration, three concave signs, flapping of nasal wings), pulmonary signs (especially wheezing sound), mental status, appetite, and other relevant indicators. This scale is is currently recognized as an objective clinical assessment method, and has been used in our study accordingly.

As shown in Table 2, there were significant differences in m-WCAS score, oxygen saturation, blood gas analysis 
Table 1 Baseline characteristics

\begin{tabular}{|c|c|c|c|c|c|c|c|c|c|c|c|}
\hline Group & $\mathrm{N}$ & $\begin{array}{c}\text { Gender\% } \\
\text { (male) }\end{array}$ & $\begin{array}{c}\text { Age } \\
\text { (month) }\end{array}$ & $\begin{array}{c}\text { Weight } \\
(\mathrm{kg})\end{array}$ & $\begin{array}{l}\text { Disease } \\
\text { course } \\
\text { (day) }\end{array}$ & $\begin{array}{c}\text { Body } \\
\text { temperature } \\
\left({ }^{\circ} \mathrm{C}\right)\end{array}$ & $\begin{array}{c}\text { Respiratory } \\
\text { rate } \\
\text { (breath/min) }\end{array}$ & $\begin{array}{l}\text { Heart rate } \\
\text { (beat/min) }\end{array}$ & $\begin{array}{l}\text { Systolic } \\
\text { blood } \\
\text { pressure } \\
(\mathrm{mmHg})\end{array}$ & $\begin{array}{l}\text { Diastolic } \\
\text { blood } \\
\text { pressure } \\
(\mathrm{mmHg})\end{array}$ & $\begin{array}{c}\text { RSV (+) } \\
(\%)\end{array}$ \\
\hline Group 1 & 51 & 60 & $4.5 \pm 2.41$ & $5.17 \pm 1.18$ & $5.44 \pm 8.79$ & $36.1 \pm 3.25$ & $57 \pm 2.01$ & $152.95 \pm 3.42$ & $92 \pm 8.10$ & $60 \pm 7.54$ & 70 \\
\hline Group 2 & 52 & 54.92 & $4.11 \pm 1.39$ & $6.09 \pm 0.75$ & $4.97 \pm 9.48$ & $37.05 \pm 1.01$ & $62 \pm 3.12$ & $159 \pm 4.61$ & $93 \pm 5.20$ & $63 \pm 4.33$ & 78.85 \\
\hline$F(H)$ value & & & 1.403 & 1.652 & 1.721 & 0.958 & 0.587 & 0.563 & 0.413 & 0.972 & \\
\hline$x^{2}$ value & & 109.28 & & & & & & & & & 110.02 \\
\hline$P$ value & & 0.925 & 0.216 & 0.836 & 0.994 & 0.833 & 0.542 & 0.921 & 0.762 & 0.827 & 0.835 \\
\hline
\end{tabular}

RSV, respiratory syncytial virus.

Table 2 Comparison of parameters of clinical manifestation before and after nCPAP treatment

\begin{tabular}{|c|c|c|c|c|c|c|c|c|c|c|}
\hline Variable & $\begin{array}{c}\text { m-WCAS } \\
\text { score }\end{array}$ & $\begin{array}{l}\text { Oxygen } \\
\text { saturation }\end{array}$ & $\begin{array}{c}\mathrm{PaO}_{2} \\
(\mathrm{mmHg})\end{array}$ & $\begin{array}{c}\mathrm{PaCO}_{2} \\
(\mathrm{mmHg})\end{array}$ & $\mathrm{PaO}_{2} / \mathrm{FiO}_{2}$ & $\begin{array}{c}\mathrm{VT} \\
(\mathrm{mL} / \mathrm{kg})\end{array}$ & $\begin{array}{c}\text { TPTEF/TE } \\
(\%)\end{array}$ & $\begin{array}{c}\text { VPTEF/VE } \\
(\%)\end{array}$ & $\mathrm{Crs} / \mathrm{kg}$ & Rrs \\
\hline $\begin{array}{l}\text { Before } \\
\text { treatment }\end{array}$ & $6.83 \pm 1.77$ & $89.38 \pm 2.84$ & $50.63 \pm 4.63$ & $59.29 \pm 2.99$ & $142.1 \pm 21.96$ & $7.14 \pm 0.69$ & $17.94 \pm 0.54$ & $18.09 \pm 0.87$ & $1.21 \pm 0.51$ & $0.19 \pm 0.034$ \\
\hline $\begin{array}{l}\text { After } \\
\text { Treatment }\end{array}$ & $5.27 \pm 0.45$ & $95.61 \pm 1.11$ & $95.96 \pm 7.51$ & $49.28 \pm 7.05$ & $197.47 \pm 31.17$ & $8.34 \pm 0.88$ & $23.85 \pm 1.75$ & $23.28 \pm 1.45$ & $1.76 \pm 0.84$ & $0.034 \pm 0.022$ \\
\hline$x^{2}$ value & 0.669 & 0.892 & 0.531 & 3.256 & 0.397 & 0.975 & 1.189 & 0.379 & 0.751 & 4.253 \\
\hline
\end{tabular}

nCPAP, nasal continuous positive airway pressure; TPTEF/TE, ratio of time to peak tidal expiratory flow to total expiratory time; VPTEF/ $\mathrm{VE}$, ratio of volume at peak tidal expiratory flow to expiratory tidal volume; Crs, respiratory system compliance; Rrs, respiratory system resistance.

parameters $\left(\mathrm{PaO}_{2}, \mathrm{PaCO}_{2}, \mathrm{PaO}_{2} / \mathrm{FiO}_{2}\right)$, pulmonary function parameters (VT, TPTEF/TE, VPTEF/VE), and respiratory mechanics parameters (Crs $/ \mathrm{kg}$, Rrs) following nCPAP intervention $(\mathrm{P}<0.05)$. This result suggested that nCPAP level could significantly reduce tachypnea, increased HR, symptoms of hypoxia, and significantly improve respiratory mechanics.

\section{Comparison of hemodynamics, blood gas analysis and m-WCAS score between different PEEP levels after nCPAP treatment}

No significant statistical differences were identified in $\mathrm{PaO}_{2}$ and $\mathrm{PaO}_{2} / \mathrm{FiO}_{2}$ among the three groups after nCPAP treatment $($ all $\mathrm{P}<0.05)$ (Table 3). However, with the increase of PEEP, the patient oxygenation improved. A significant difference was found in $\mathrm{PaCO}_{2}$ among the three groups after treatment $(\mathrm{P}<0.05)$, with the highest in the group 1 and the lowest in the group 2. This difference suggested that higher PEEP was more effective in correcting $\mathrm{CO}_{2}$ to a certain point, after which increasing PEEP did not result in improved $\mathrm{CO}_{2}$ levels. This finding may suggest when exogenous PEEP exceeded a certain level, it might lead to an increase in functional residual capacity in the body that is not conducive to $\mathrm{CO}_{2}$ excretion. Moreover, it might even lead to a decrease in negative intrathoracic pressure and and an increase of pulmonary vascular resistance, potentially causing mechanical ventilation-related lung injury.

The m-WCAS score was significantly different among the three groups after treatment $(\mathrm{P}<0.05)$, with the lowest score in the group 2 and the highest in the group 3. This finding suggested that PEEP of $6 \mathrm{cmH}_{2} \mathrm{O}$ had the most marked clinical improvement and efficacy. Additionally, the systolic and diastolic blood pressures of the three groups remained within the normal range for all three groups, suggesting no significant effect on hemodynamics caused by 
Table 3 Comparison of hemodynamics, blood gas analysis and m-WCAS score between different PEEP levels after nCPAP treatment

\begin{tabular}{|c|c|c|c|c|c|c|c|}
\hline Group & $\mathrm{N}$ & m-WCAS score & $\begin{array}{c}\mathrm{PaO}_{2} \\
(\mathrm{mmHg})\end{array}$ & $\begin{array}{l}\mathrm{PaCO}_{2} \\
(\mathrm{mmHg})\end{array}$ & $\mathrm{PaO}_{2} / \mathrm{FiO}_{2}$ & $\begin{array}{l}\text { Systolic blood pressure } \\
\qquad(\mathrm{mmHg})\end{array}$ & $\begin{array}{l}\text { Diastolic blood pressure } \\
\qquad(\mathrm{mmHg})\end{array}$ \\
\hline Group 1 & 51 & $5.69 \pm 0.30$ & $86.38 \pm 6.68$ & $50.31 \pm 6.00$ & $175.32 \pm 32.35$ & $89 \pm 10.21$ & $55 \pm 8.16$ \\
\hline Group 3 & 49 & $5.92 \pm 0.26$ & $102.24 \pm 8.62$ & $52.97 \pm 8.88$ & $216.55 \pm 39.78$ & $94 \pm 8.13$ & $62 \pm 6.25$ \\
\hline$P$ value & & 0.024 & 0.247 & 0.045 & 0.681 & 0.0571 & 0.0389 \\
\hline
\end{tabular}

PEEP, positive end-expiratory pressure; nCPAP, nasal continuous positive airway pressure.

Table 4 Comparison of respiratory mechanics parameters between different PEEP levels after nCPAP treatment

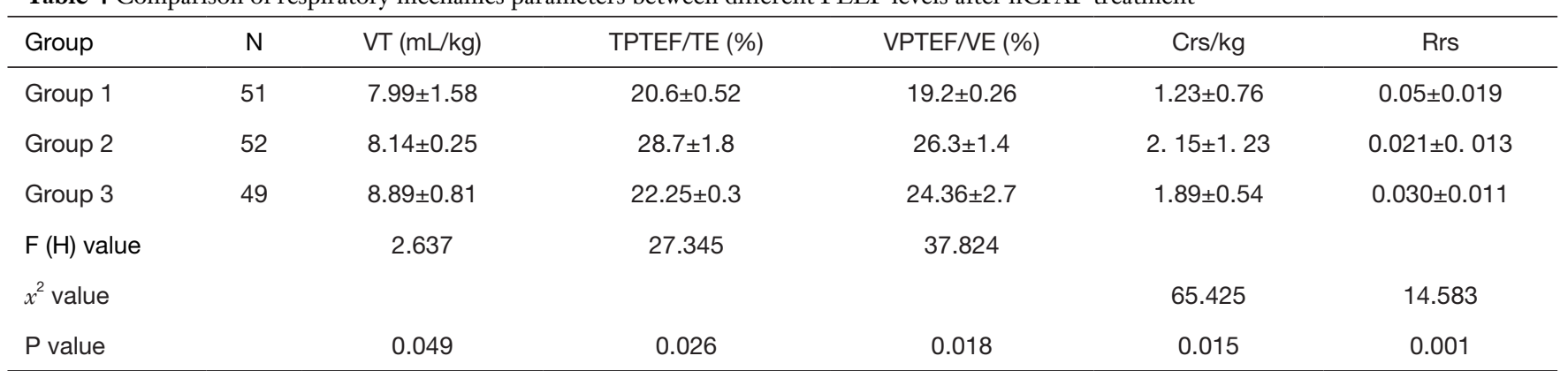

PEEP, positive end-expiratory pressure; nCPAP, nasal continuous positive airway pressure; TPTEF/TE, ratio of time to peak tidal expiratory flow to total expiratory time; VPTEF/VE, ratio of volume at peak tidal expiratory flow to expiratory tidal volume; Crs, respiratory system compliance; Rrs, respiratory system resistance.

nCPAP treatment at the prescribed PEEP levels. Diastolic blood pressure was significantly different between the three groups after treatment $(\mathrm{P}<0.05)$, with the highest in the group 3 . The children in group 3 generally presented varying degrees of poor compliance, such as paroxysmal irritability and crying (approximately $87 \%$ ). These results suggested that after a certain point, increasing PEEP level resulted in poorer efficacy and compliance with treatment.

\section{Comparison of respiratory mechanics parameters between different PEEP levels after nCPAP treatment}

Significant statistical differences were found in VT, TPTEF/TE, VPTEF/VE, Crs/kg, and Rrs between the three groups (all $\mathrm{P}<0.05$ ) (Table 4). With increasing PEEP, VT progressively increased, while VPTEF/VE and TPTEF/TE-which are important indicators of airway obstruction, especially in small airways-did not increase. The change of VPTEF/VE was similar to that of TPTEF/ TE. When PEEP level reached $6 \mathrm{cmH}_{2} \mathrm{O}$, TPTEF/TE and
VPTEF/VE increased most significantly, suggesting the greatest improvement in airway obstruction at this level. Rrs and Crs $/ \mathrm{kg}$ - evaluation parameters of pulmonary static compliance-were improved most significantly in the group 2 , suggesting that pulmonary static compliance improved most at this level, with decreasing airway resistance, reducing respiratory muscle energy consumption and optimising the respiratory mechanics.

\section{Discussion}

Bronchiolitis is still regarded as one of the most common diseases in children aged under 2 years-in particular, in infants less than 6 months of age-causing the heaviest psychological and economic burden on families in the world $(6,10)$. More than $15 \%$ of bronchiolitis cases are severe, and this is even higher in developing countries (11). The pathology of this disease is acute airway inflammation, mucosal edema, epithelial cell necrosis, increased mucus secretion, which result in bronchial stenosis and obstruction. 
Its main clinical signs include asthma, tachypnea, three concave signs, prolonged expiratory phase on auscultation, audible wheezing sound, and fine moist rales. Bronchiolitis causes obstruction of airways, especially small airways, thus increasing intrinsic PEEP. At present, the traditional treatment of bronchiolitis is based on symptomatic and supportive treatment such as oxygen therapy $(1,4,11)$.

Numerous studies have shown that nCPAP was effective in overcoming intrinsic PEEP, reducing airway resistance, reducing airway collapse (especially terminal airways), reducing $\mathrm{CO}_{2}$ retention, relieving respiratory muscle fatigue, as well as improving ventilation-blood flow ratio $(6,12)$. nCPAP is conducted in children with spontaneous breathing as it is more consistent with the normal breathing cycle than invasive ventilation. Due to the advantages, $\mathrm{nCPAP}$ is being increasingly used in pediatric respiratory disease in the clinical setting; however, PEEP level settings vary considerably for different diseases. Previous research on PEEP has focused on clinical parameters such as patient comfort and blood gas analysis $(3,13,14)$; however, there are few studies that investigated the differences of different PEEP levels in the clinic application $(15,16)$ - especially prospective studies — and no such study has been conducted in China.

In this before-after prospective study, we compared the clinical efficacy of different PEEP levels. Blood gas analysis, pulmonary function parameters, and respiratory mechanics were assessed. The results showed that nCPAP treatment could effectively improve RR, pulmonary signs (especially wheezing sound), general condition (such as mental status and appetite), oxygenation, and correct $\mathrm{CO}_{2}$ retention. This treatment also shortened hospital length of stay. Additionally, it was found that during nCPAP treatment, PEEP at $6 \mathrm{cmH}_{2} \mathrm{O}$ was the optimal level to improve clinical signs and symptoms (m-WCAS score), correct $\mathrm{CO}_{2}$ retention $\left(\mathrm{PaCO}_{2}\right)$, improve oxygenation $\left(\mathrm{PaO}_{2}\right.$ and $\mathrm{PaO}_{2} / \mathrm{FiO}_{2}$ ), reduce small airway obstruction (TPTEF/TE and VPTEF/VE), reduce airway resistance, and improve lung compliance; however, increasing PEEP to $7 \mathrm{cmH}_{2} \mathrm{Odid}$ not appear to have a satisfactory effect on these parameters, with increased RR, tachypnea, crying, and even refusal to eat observed in this group.

As and the development of the management of severe bronchiolitis, nCPAP has been introduced into international treatment guidelines. Traditionally, PEEP level has been roughly estimated based on the improvement of the patient's clinical symptoms and signs $(17,18)$. Appropriate PEEP can reduce the pressure difference between the airway and alveoli in patients with chronic obstructive pulmonary disease, reduce inspiratory load and respiratory power consumption, and improve patient-ventilator synchrony. In this study, objective measures of pulmonary function and respiratory mechanics and subjective measures of clinical symptoms and signs were observed. Based on a series of parameters that reflect pathophysiological changes in respiratory disease, the optimal PEEP level was determined, providing parameters for evidence-based treatment of bronchiolitis.

Bronchiolitis usually affects infants under 1 year of age, and particularly affects those aged 2-6 months. The use of passive flow-volume (PFV) techniques could reveal respiratory diseases (for example, small airway lesions) in young children, especially airway obstructive lesions. Additionally, the technique of PFV can overcome poor respiratory compliance in infants and young children. PFV does not require patient cooperation and has good repeatability, which can provide objective indicators of volume, expiratory flow rate and thoracoabdominal movement during normal respiration, which can guide clinical practice. These indicators have been used to replace adult pulmonary function parameters such as FEV1/VC in the diagnosis and treatment of asthma in infants and young children (19). Different degrees of obstructive ventilatory disorder of the small airways are the main symptom observed in patients with acute bronchiolitis, and TPTEF/ TE and VPTEF/VE provide a sensitive measure of changes in airway obstruction (20). In this study, TPTEF/TE and VPTEF/VE were significantly decreased in the acute phase and in more severe asthmatic symptoms; these two parameters then increased markedly after the improvement of obstruction. Additionally, we also found that compared with the other two levels, PEEP at $6 \mathrm{cmH}_{2} \mathrm{O}$ led to the most significant increase of TPTEF/TE and VPTEF/VE $(\mathrm{P}<0.05)$. Combined with the clinical symptom score, $\mathrm{PaO}_{2}$, $\mathrm{PaCO}_{2}$, we could suggest that airway obstruction is most significantly improved and the clinical efficacy is the most satisfactory when PEEP was at $6 \mathrm{cmH}_{2} \mathrm{O}$.

Respiratory movement is a mechanical process which occurs under central regulation, whereby the respiratory muscles contract and relax to enable air inhalation and exhalation. Severe bronchiolitis causes airway mucosal edema, necrosis and shedding, as well as mucus secretion, resulting in airway obstruction, especially in the small airways. Consequently, respiratory muscle effort increases to overcome resistance, leading to significant abnormalities in respiratory mechanics. Therefore, the use of respiratory 
mechanics monitoring is crucial to guide the regulation mechanical ventilation parameters (21). PEEP could be adjusted on the basis of the pulmonary pressure-volume curve, for the optimal volume of tidal breathing. Due to the physiological characteristics of infants and young children and their poor active cooperation, static Crs can be used as a simple measure of respiratory mechanics to assist in assessing disease severity and monitoring changes in patient condition $(22,23)$. Optimising PEEP level will achieve the greatest oxygen transport and lung compliance, while reducing dead space, in children during mechanical ventilation. At a PEEP level of $6 \mathrm{cmH}_{2} \mathrm{O}$, Crs was found to be highest $(2.15 \pm 1.23)$ and Rrs was at the lowest $(0.021 \pm 0.013)$, suggesting that this PEEP level could maximize static compliance and minimize airway resistance. Therefore, it can be inferred that a PEEP level of $6 \mathrm{cmH}_{2} \mathrm{O}$ optimises respiratory mechanics with relatively low respiratory muscle effort.

While increasing PEEP level effectively improved oxygenation and reduced $\mathrm{CO}_{2}$ retention, $\mathrm{PaO}_{2}(96.25 \pm 7.24)$ at PEEP of $7 \mathrm{cmH}_{2} \mathrm{O}$ was not significantly increased compared with $\mathrm{PaO}_{2}$ at $6 \mathrm{cmH}_{2} \mathrm{O}(96.25 \pm 7.24)$. Additionally, an excessive PEEP level did not necessarily obtain better therapeutic effect or respiratory mechanics, but could lead to increase airway resistance resulting in limiting $\mathrm{CO}_{2}$ excretion and affecting normal spontaneous breathing. Therefore, at an excessive PEEP level, the children were prone to dysphoria, crying, decreased compliance, and even further $\mathrm{CO}_{2}$ retention. Our findings were not consistent with the conclusion of Dadlez et al. (16), but were consistent with that of Hao et al. (15). This difference was considered to be related to different study sample size, observation and evaluation indicators.

This study has some limitations, including the measures used to assess respiratory mechanics. Further in-depth investigation could be carried out using additional respiratory mechanics measures such as esophageal pressures (Pes) and gastric pressures $(\mathrm{Pga})(16,23)$.

In summary, nCPAP with a PEEP level of $6 \mathrm{cmH}_{2} \mathrm{O}$ showed the most optimal improvement in clinical symptoms, oxygenation, correction of $\mathrm{CO}_{2}$ retention, airway obstruction, lung compliance and respiratory muscle effort in neonates with bronchiolitis. Therefore, $6 \mathrm{cmH}_{2} \mathrm{O}$ is suggested as optimal PEEP level in the clinical application of nCPAP treatment for severe bronchiolitis.

\section{Acknowledgments}

Funding: Medical research program of Chongqing Health and Family Planning Commission (2016MSXM034).

\section{Footnote}

Reporting Checklist: The authors have completed the STROBE reporting checklist. Available at https://dx.doi. org/10.21037/tp-21-205

Data Sharing Statement: Available at https://dx.doi. org/10.21037/tp-21-205

Conflicts of Interest: All authors have completed the ICMJE uniform disclosure form (available at https://dx.doi. org/10.21037/tp-21-205). The authors have no conflicts of interest to declare.

Ethical Statement: The authors are accountable for all aspects of the work in ensuring that questions related to the accuracy or integrity of any part of the work are appropriately investigated and resolved. All procedures performed in this study involving human participants were in accordance with the Declaration of Helsinki (as revised in 2013). The study was approved by the institutional review board Children's Hospital Chongqing Medical University (No. 056/2016) and written informed consent was obtained from all patients.

Open Access Statement: This is an Open Access article distributed in accordance with the Creative Commons Attribution-NonCommercial-NoDerivs 4.0 International License (CC BY-NC-ND 4.0), which permits the noncommercial replication and distribution of the article with the strict proviso that no changes or edits are made and the original work is properly cited (including links to both the formal publication through the relevant DOI and the license). See: https://creativecommons.org/licenses/by-nc-nd/4.0/.

\section{References}

1. Duke T. CPAP: a guide for clinicians in developing countries. Paediatr Int Child Health 2014;34:3-11.

2. Chetan C, Basu S. Nasal Continuous Positive Airway Pressure for Bronchiolitis. Indian Pediatr 2018;55:438.

3. Shen Y, Wang B, Chao W, et al. Clinical application of $n$ CPAP as pre-emptive ventilatory support strategy in severe bronchiolitis. Journal of Practical Medicine 2015;31:2870.

4. Medina A, Del Villar-Guerra P, Modesto I Alapont V. CPAP support should be considered as the first choice in 
severe bronchiolitis. Eur J Pediatr 2019;178:119-20.

5. Lal SN, Kaur J, Anthwal P, et al. Nasal Continuous Positive Airway Pressure in Bronchiolitis: A Randomized Controlled Trial. Indian Pediatr 2018;55:27-30.

6. Jin HX, Teng Y, Dai J, et al. Expert consensus on the prevention, diagnosis and treatment of cold injury in China, 2020. Mil Med Res 2021;8:6.

7. Subspecialty Group of Emergency Medicine, the Society of Pediatries, Chinese Medical Association; Subspecialty Group of Pediatries, the Society of Emergency Medicine, Chinese Medical Association; Pediatric Emergency Medicine Physicians, Chinese Medical Doctor Association. Expert consensus on clinical application of noninvasive continuous positive airway pressure in children. Zhonghua Er Ke Za Zhi 2016;54:649-52.

8. Perret JL, Walters EH. Cigarette smoking and lung function decline beyond quitting. Ann Transl Med 2020;8:1531.

9. Wang EE, Milner RA, Navas L, et al. Observer agreement for respiratory signs and oximetry in infants hospitalized with lower respiratory infections. Am Rev Respir Dis 1992;145:106-9.

10. Jat KR, Mathew JL. Continuous positive airway pressure (CPAP) for acute bronchiolitis in children. Cochrane Database Syst Rev 2019;1:CD010473.

11. Fedor KL. Noninvasive Respiratory Support in Infants and Children. Respir Care 2017;62:699-717.

12. Cruces P, González-Dambrauskas S, Quilodrán J, et al. Respiratory mechanics in infants with severe bronchiolitis on controlled mechanical ventilation. BMC Pulm Med 2017;17:129.

13. Milési C, Matecki S, Jaber S, et al. $6 \mathrm{cmH}_{2} \mathrm{O}$ continuous positive airway pressure versus conventional oxygen therapy in severe viral bronchiolitis: a randomized trial. Pediatr Pulmonol 2013;48:45-51.

14. Figueroa L, Laffaye F. Early use of continuous positive airway pressure in the treatment of moderate to severe acute lower respiratory tract infections among

Cite this article as: Yin L, Li L, Peng D, Chen W. Optimal level of positive end-expiratory pressure during nasal continuous airway pressure for severe bronchiolitis: a prospective study. Transl Pediatr 2021;10(7):1843-1850. doi: 10.21037/tp-21-205 patients younger than 2 years old. Arch Argent Pediatr 2017;115:277-81.

15. Hao Z, Yufen W, Jianfeng H, et al. Expert consensus on pulmonary function test and evaluation in children. 2014;32:104-14.

16. Dadlez NM, Esteban-Cruciani N, Khan A, et al. Risk Factors for Respiratory Decompensation Among Healthy Infants With Bronchiolitis. Hosp Pediatr 2017;7:530-5.

17. Gupta S, Donn SM. Continuous positive airway pressure: Physiology and comparison of devices. Semin Fetal Neonatal Med 2016;21:204-11.

18. Figueroa L, Laffaye F. Early use of continuous positive airway pressure in the treatment of moderate to severe acute lower respiratory tract infections among patients younger than 2 years old. Arch Argent Pediatr 2017;115:277-81.

19. Xie Z, Chai M, Gu W, Yuan H. Changes in fractional exhaled nitric oxide, exhaled carbon monoxide and pulmonary function during the acute attack, treatment and remission phases of pediatric asthma. Transl Pediatr 2020;9:784-94.

20. Ai T, Wang L, Luo R, et al. Effects of sublingual-specific immunotherapy on pulmonary function and exhaled nitric oxide levels in asthmatic children with and without allergic rhinitis. Transl Pediatr 2020;9:686-94.

21. Cruces P, González-Dambrauskas S, Quilodrán J, et al. Respiratory mechanics in infants with severe bronchiolitis on controlled mechanical ventilation. BMC Pulm Med 2017;17:129.

22. Dadlez NM, Esteban-Cruciani N, Khan A, et al. Risk Factors for Respiratory Decompensation Among Healthy Infants With Bronchiolitis. Hosp Pediatr 2017;7:530-5.

23. Gupta S, Donn SM. Continuous positive airway pressure: Physiology and comparison of devices. Semin Fetal Neonatal Med 2016;21:204-11.

(English Language Editor: M. Hawkins) 